\title{
Significance of chronic cough as a defence mechanism or a symptom in elderly patients with aspiration and aspiration pneumonia
}

\section{To the Editors:}

In a recent issue of the European Respiratory Journal, MORICE and the European Respiratory Society (ERS) Task Force committee members [1] comprehensively summarised the diagnosis and management of chronic cough in both adults and children. However, they have totally neglected the features, diagnosis and management of chronic cough in the elderly [1].

Although cough is one of the most common symptoms for which patients seek medical attention from primary care physicians and pulmonologists all over the world and is associated with deterioration in patients' quality of life [1], the concise and distinct guideline is not extensively introduced. Thus, the recent ERS Task Force report "The diagnosis and management of chronic cough" is very helpful and meaningful for chest physicians as well as primary care physicians. However, age-related changes in cough reflex and the protective roles of cough as the defence mechanism of aspiration in older patients are not argued in the report.

PALOMBINI et al. [2] reported that asthma, postnasal drip syndrome (PNDS) and gastro-oesophageal reflux disease (GERD), alone or in combination, were responsible for $\geqslant 90 \%$ of the causes of chronic cough. They proposed that asthma, PNDS and GERD should be called a pathological triad in chronic cough in adults [2]. However, in older patients, the causes of chronic cough may be more complicated. Age-related changes in cough reflex may affect the causes and therapeutic efficacy of chronic cough [3]. Furthermore, the protective role of cough as the defence mechanism of aspiration is very important for the pathogenesis of chronic cough in older patients. Owing to the increasing number of the elderly in the population, many pulmonologists and geriatricians recognised that silent aspiration might be very important for the pathogenesis of aspiration pneumonia and nosocomial pneumonia in older patients [4-7]. The prevalence of stroke, chronic obstructive pulmonary disease, sleep apnoea, gastrooesophageal reflux, sedatives and/or hypnotics usage, postgastrectomy and mechanical ventilation are increased in the aged population and these are believed to increase the risk of aspiration [4-7]. As pneumonia is in principle prevented by the defence mechanisms, such as upper airway reflexes, mucociliary clearance and phagocytosis by alveolar macrophages, agedependent declines of upper airway reflexes may be one of the pathophysiological features of aspiration pneumonia in older subjects. Elderly persons appear to have slowed clearance of particles from the airway probably due to impaired mucociliary function that accompanies ageing. However, in our experience, cough reflexes rather than swallowing reflex or mucociliary clearance are of the utmost importance for preventing aspiration in elderly patients. In fact, a markedly decreased cough reflex was observed in elderly patients with aspiration pneumonia [3,4]. Inversely, there is growing evidence that angiotensin-converting enzyme (ACE) inhibitors have beneficial effects on the prevention of pneumonia in elderly patients by improving both the impaired swallowing reflex and disturbed cough reflex $[8,9]$. Although the elevated levels of bradykinin and substance $P$ by ACE inhibitors are thought to be the source of the cough, bradykinin and substance P play a role in setting the threshold for the cough and swallowing reflex in humans, resulting in reduction of the occurrence of pneumonia in the elderly. The beneficial effects of ACE inhibitors for older subjects with the risk of aspiration pneumonia should be widely noted $[8,9]$.

In addition, we have recently demonstrated that recurrent silent aspiration causes diffuse aspiration bronchiolitis (DAB), which is characterised as a chronic inflammation of bronchioles accompanying a foreign body reaction $[3,10]$. The patients with DAB mostly demonstrated signs of bronchorrhoea, cough, bronchospasm and dyspnoea in the case of food intake. The chronic cough in association with food intake is often misdiagnosed as bronchial asthma in the elderly. The chronic cough in $\mathrm{DAB}$ does not respond to $\beta$-adrenergic bronchodilators or to inhaled steroids. The swallowing rehabilitation and temporally i.v. alimentation are the most effective way to reduce the symptoms in DAB.

Although chronic cough is an untoward symptom in adults as well as elderly subjects, the protective roles of cough reflex on the development of aspiration pneumonia in older patients should be carefully considered by all physicians. Hopefully, the next European Respiratory Society Task Force report will include the clinical significance of chronic cough as a defence mechanism or a symptom in elderly patients with aspiration and aspiration pneumonia.

S. Teramoto, T. Ishii, H. Yamamoto, Y. Yamaguchi, R. Namba, Y. Hanaoka, M. Takizawa, T. Okada, M. Ishii and Y. Ouchi Dept of Geriatric Medicine, The University of Tokyo Hospital, Tokyo, Japan. 


\section{REFERENCES}

1 Morice AH, and ERS Task Force committee members, The diagnosis and management of chronic cough. Eur Respir J 2004; 24: 481-492.

2 Palombini BC, Villanova CAC, Araujo E, et al. A pathologic triad in chronic cough: asthma, postnasal drip syndrome, and gastroesophageal reflux disease. Chest 1999; 116: 279-284.

3 Teramoto S, Matsuse T, Ouchi Y. Clinical significance of cough as a defence mechanism or a symptom in elderly patients with aspiration and diffuse aspiration bronchiolitis [letter]. Chest 1999; 115: 602-603.

4 Teramoto S, Yamamoto H, Yamaguchi Y, Ouchi Y, Matsuse T. A novel diagnostic test for the risk of aspiration pneumonia in the elderly. Chest 2004; 125: 801-802.

5 Teramoto S, Yamamoto H, Yamaguchi Y, Kawaguchi H, Ouchi Y. Nosocomial infections in adult intensive-care units. Lancet 2003; 362: 493.

6 Teramoto S, Kume H, Ouchi Y. Altered swallowing physiology and aspiration in COPD. Chest 2002; 122: 1104-1105.

7 Marumo K, Homma S, Fukuchi Y. Postgastrectomy aspiration pneumonia. Chest 1995; 107: 453-456.

8 Sekizawa K, Matsui T, Nakagawa T, Nakayama K, Sasaki H. ACE inhibitors and pneumonia. Lancet 1998; 352: 1069.

9 Teramoto S, Kume H, Fukuchi Y. Antihypertensive drugs in Japan. Lancet 2001; 357: 720-721.

10 Matsuse T, Oka T, Kida K, et al. Importance of diffuse aspiration bronchiolitis caused by chronic occult aspiration in the elderly. Chest 1996; 110: 1289-1293.

\section{From the author:}

Teramoto and colleagues have completely misunderstood the purpose of the ERS Task Force on diagnosis and management of chronic cough [1]. The document deals with patients who have had a cough for $>8$ weeks. It is not about patients who can't cough. To suggest in their opening paragraph that we neglect cough in the elderly is simply disingenuous. We deliberately separated chronic cough in children from that in adults since the aetiology is different. However, in adults the causes and treatment of chronic cough are not age related and the elderly were frequent attendees in the 13 studies quoted in table 1 which presents the accumulated experience of specialist cough clinics [1].

Decreased cough and aspiration are important clinical problems but they were not the subject of our discussions. Clearly neurological illness [2,3] and anatomical abnormality [4] can increase the likelihood of aspiration but this is neither age specific nor relevant to clinicians dealing with patients who present with isolated chronic cough.

Finally, an important function of documents such as the Task Force report is to provide a balanced overview of the literature. Teramoto and colleagues seem to have concentrated largely on their own work, which perhaps goes some way to explain the current debate.

\section{A.H. Morice}

Division of Academic Medicine, University of Hull, Castle Hill Hospital, Cottingham, UK.

\section{REFERENCES}

1 Morice $\mathrm{AH}$ and committee members. The diagnosis and management of chronic cough. Eur Respir J 2004; 24: 481-492.

2 Fontana GA, Pantaleo T, Lavorini F, Benvenuti F, Gangemi S. Defective motor control of coughing in Parkinson's disease. Am J Respir Crit Care Med 1998; 158: 458-464.

3 Dicpinigaitis PV, Grimm DR, Lesser M. Cough reflex sensitivity in subjects with cervical spinal cord injury. Am J Respir Crit Care Med 1999; 159: 1660-1662.

4 Fontana GA, Pantaleo T, Lavorini F, Mutolo D, Polli G, Pistolesi M. Coughing in laryngectomized patients. Am J Respir Crit Care Med 1999; 160: 1578-1584.

DOI: $10.1183 / 09031936.04 .00114704$

\section{The hepatopulmonary syndrome: NO way out?}

\section{To the Editors:}

The hepatopulmonary syndrome (HPS) is defined by the triad of chronic liver disease, abnormal pulmonary gas exchange (low arterial oxygen tension $\left(\mathrm{Pa}_{\mathrm{a}} \mathrm{O}_{2}\right)$ and transfer factor of the lung for carbon monoxide), and intrapulmonary vascular dilatation [1]. The recent editorial on HPS [2] suggests that "hunting endogenous vasodilators that reduce pulmonary vascular tone logically became a sound strategy for those whose quest was to unravel the missing 'molecular' link between the diseased liver and the affected lung". But, is this strategy actually so logical? The key feature of the intrapulmonary vascular dilatation in HPS is the intrapulmonary shunt shown physiologically by a low $\mathrm{Pa}_{\mathrm{a}} \mathrm{O}_{2}$ after $100 \%$ oxygen breathing, and anatomically by the passage of radiolabelled albumin macroaggregates $(20-60 \mu \mathrm{m}$ in diameter), or echobubbles, through the pulmonary capillary bed [3]. The striking feature pathologically is gross dilatation of capillaries in the alveolar septum, diameters of $100 \mu \mathrm{m}$, as compared with the normal $7-15 \mu \mathrm{m}$ being described [4]. Is it likely that endogenous vasodilators are responsible for "relaxing" alveolar capillaries to such an extent? Of course, endogenous vasodilators may play a part in "remodelling" these capillaries.

With regard to pulmonary gas exchange, two factors seem to operate in severe hepatopulmonary syndrome: 1) a 